\title{
Best practices for setting up a repository of phenotypic data for European germplasm holdings
}

\author{
Stephan Weise ${ }^{\ddagger}$, Markus Oppermann ${ }^{\ddagger}$ \\ ‡ Leibniz Institute of Plant Genetics and Crop Plant Research (IPK), Seeland, Germany
}

Corresponding author: Stephan Weise (weise@ipk-gatersleben.de)

Received: 23 Mar 2018| Published: 22 May 2018

Citation: Weise S, Oppermann M (2018) Best practices for setting up a repository of phenotypic data for

European germplasm holdings. Biodiversity Information Science and Standards 2: e25223.

https://doi.org/10.3897/biss.2.25223

\begin{abstract}
The European Search Catalogue for Plant Genetic Resources, EURISCO, provides information about more than 1.9 million accessions of crop plants and their wild relatives, preserved ex situ by almost 400 institutes in Europe and beyond (Weise et al. 2017). EURISCO, which is being maintained on behalf of the European Cooperative Programme for Plant Genetic Resources, is based on a network of National Inventories of 43 member countries. It represents an important effort for the preservation of the world's agrobiological diversity by providing information about the large genetic diversity kept by the collaborating institutions.
\end{abstract}

Besides the classical passport data, in 2016, EURISCO started to additionally collect phenotypic data about the documented germplasm accessions. The selection of genebank material for both research and breeding purposes is increasingly carried out through the selection of specific phenotypic values, e.g. flowering time or plant height. Thus, these data are of high importance to users of plant genetic resources (PGR) since they determine the value of the respective germplasm. However, because there are no commonly agreed standards existing within the genebank community, this kind of data is very difficult to handle. In this context, the challenges range from synonymous/homonymous descriptor names over different rating scales to different/insufficient amounts of meta information, thus hampering both integration and cross-experiment comparison of data. 
The presentation will illustrate the approach followed within EURISCO, together with the challenges resulting therefrom. Using this as a solid basis for a discussion about the utilization of this kind of data, the presentation shall be regarded as a call for cooperation.

\section{Keywords}

ECPGR, EURISCO, plant genetic resources, information system, phenotypic data

\section{Presenting author}

Stephan Weise

\section{References}

Weise S, Oppermann M, Maggioni L, Hintum Tv, Knüpffer H (2017) EURISCO: The European search catalogue for plant genetic resources. Nucleic Acids Research 45 (D1): D1003-D1008. https://doi.org/10.1093/nar/gkw755 